\title{
Fatigue life estimation in welded joints under multiaxial loadings
}

\author{
Andrea Carpinteri, Andrea Spagnoli, Sabrina Vantadori \\ University of Parma, Department of Civil and Environmental Engineering and Architecture, Via G.P. Usberti 181/A, 43100 \\ Parma, Italy; andrea.carpinteri@unipr.it
}

\begin{abstract}
RIASSUNTO. Le giunzioni saldate sono frequentemente zone di innesco di fessure che possono poi provocare la crisi per fatica dell'intera struttura. Stati tensionali e deformativi biassiali o triassiali sono presenti in prossimità delle giunzioni saldate a causa della concentrazione indotta dalla geometria della giunzione stessa, dal processo di saldatura e/o dalla presenza di carichi multiassiali. La determinazione della vita a fatica di giunzioni saldate in presenza di carichi multiassiali ciclici proporzionali può essere eseguita adottando criteri locali basati su ipotesi convenzionali (Criterio di Mises o Criterio di Tresca). In presenza di carichi ciclici multiassiali non proporzionali, invece, è stato osservato sperimentalmente che, valutando la vita a fatica attraverso ipotesi convenzionali, si giunge a previsioni che non sono a favore di sicurezza. Un criterio è stato proposto dagli autori per determinare la vita a fatica di componenti strutturali soggetti a stati tensionali multiassiali. Il criterio è stato inizialmente sviluppato per i componenti lisci e intagliati e poi esteso, con opportune modifiche, ai componenti saldati. La determinazione della vita a fatica viene eseguita considerando una funzione quadratica in cui compaiono l'ampiezza della componente tangenziale di tensione (agente sul piano critico) e l'ampiezza e il valore medio della componente normale di tensione (agente sul piano critico). Scopo di questo lavoro è il confronto tra la previsione della vita a fatica ottenuta mediante il presente criterio in termini di tensioni nominali e la vita a fatica sperimentale per dati relativi a prove biassiali di fatica reperibili in letteratura.
\end{abstract}

ABSTRACT. Welded joints are frequently locations for cracks initiation and propagation that may cause fatigue failure of engineering structures. Biaxial or triaxial stress-strain states are present in the vicinity of welded joints, due to local geometrical constraints, welding processes and/or multiaxial external loadings. Fatigue life evaluation of welded joints under multiaxial proportional (in-phase) cyclic loading can be performed by using conventional hypotheses (e.g. see the von Mises criterion or the Tresca criterion) on the basis of local approaches. On the contrary, the fatigue life predictions of welded joints under non-proportional (out-ofphase) cyclic loading are generally unsafe if these conventional hypotheses are used. A criterion initially proposed by the authors for smooth and notched structural components has been extended to the fatigue assessment of welded joints. In more detail, fatigue life of welded joints under multiaxial stress states can be evaluated by considering a nonlinear combination of the shear stress amplitude (acting on the critical plane) and the amplitude and the mean value of the normal stress (acting on the critical plane). In the present paper, fatigue lifetimes predicted through the proposed criterion are compared with experimental fatigue life data available in the literature, related to fatigue biaxial tests.

KEYWORDs. Welded joints; nominal stresses; lifetime prediction; critical plane approach

\section{INTRODUCTION}

$\mathrm{M}$

etallic structural components are very often jointed together by welds, and such joints are frequently critical locations for fatigue failures. That has yielded a wealth of research studies aiming at predicting the fatigue strength of welded joints. 
Several methods are available in the literature to perform fatigue strength and service life assessment of welded joints under uniaxial fatigue loading [1]. The most common uniaxial approach, encapsulated by most of the standard codes in force for metallic structures [2], proceeds by comparing the nominal stress amplitudes applied to the joint with the nominal stress values obtained from S-N curves. Local approaches based on local parameters have recently attracted increasing attention in the research community: for example, structural stress and strain approaches [3,4], notch stress and strain approaches [5,6], fracture mechanics approaches [7,8], critical distance approaches [9,10]. The fatigue assessment of welded joints employing local parameters becomes more complex when multiaxial fatigue stress-strain states are present in the vicinity of welded joints. When a weld structure is subjected to in-phase multiaxial fatigue loading, the stress-strain state can be reduced to an equivalent stress/strain based on conventional hypotheses used for static strength evaluation (e.g. see the von Mises criterion or the Tresca criterion). However, some experimental results [11] on welded steel joints show a decrease of fatigue life in presence of out-of-phase multiaxial loadings as compared to fatigue life under in-phase multiaxial loadings.

The critical plane-based multiaxial fatigue criterion proposed by Carpinteri and Spagnoli (the C-S criterion) for smooth and notched specimens [12-17] has recently been extended to welded structural components by employing the nominal stresses [18]. In the present paper, a comparison between lifetime predictions and experimental data available in the literature [11, 19-21] is carried out, for both in-phase and out-of-phase biaxial cyclic loadings with constant amplitude.

\section{THE C-S CRITERION}

multiaxial fatigue criterion based on the so-called critical plane approach has been proposed by Carpinteri and Spagnoli to estimate the high-cycle fatigue strength (either endurance limit or fatigue lifetime) of both smooth 1 and notched structural components [12-17]. The main steps of the C-S criterion are as follows:

(i) Averaged directions of the principal stress axes are determined on the basis of their instantaneous directions;

(ii) The orientation of the initial (hereafter termed critical) crack plane and that of the final fracture plane are linked to the averaged directions of the principal stress axes (two material parameters are required at this step: fatigue limit $\sigma_{a f,-1}$ under fully reversed normal stress, and fatigue limit $\tau_{a f,-1}$ under fully reversed shear stress);

(iii) The mean value and the amplitude (in a loading cycle) of the normal stress and shear stress, respectively, acting on the critical plane are computed;

(iv) The fatigue strength estimation is performed via a quadratic combination of normal and shear stress components acting on the above critical plane (in the case of finite-life fatigue evaluation, two further material parameters are required at this step: the slope $m$ of the S-N curve in the high-cycle regime under fully reversed normal stress, and the slope $m^{*}$ of the $\mathrm{S}-\mathrm{N}$ curve in the high-cycle regime under fully reversed shear stress).

In the following sub-sections, the C-S criterion is briefly reviewed, and an extension to the fatigue assessment of welded structural components under in- and out-of-phase loadings is discussed [18].

\section{Averaged directions of the principal stress axes}

At a given material point $\mathrm{P}$, the direction cosines of the instantaneous principal stress directions 1,2 and 3 (being $\left.\sigma_{1}(t) \geq \sigma_{2}(t) \geq \sigma_{3}(t)\right)$ with respect to a fixed PXYZ frame can be worked out from the time-varying stress tensor $\sigma(t)$.

Then the orthogonal coordinate system P123 with origin at point $\mathrm{P}$ and axes coincident with the principal stress directions (Fig.1) can be defined through the 'principal Euler angles', $\phi, \theta, \psi$, which represent three counter-clockwise sequential rotations around the $\mathrm{Z}$-axis, $\mathrm{Y}^{\prime}$-axis and 3 -axis, respectively $(0 \leq \phi<2 \pi ; 0 \leq \theta \leq \pi ; 0 \leq \psi<2 \pi)$. The procedure to obtain the principal Euler angles from the direction cosines of the principal stress directions consists of two stages, described in Ref.[12].

The averaged directions of the principal stress axes $\hat{1}, \hat{2}$ and $\hat{3}$ are obtained from the averaged values $\hat{\phi}, \hat{\theta}, \hat{\psi}$ of the principal Euler angles. Such values are computed by independently averaging the instantaneous values $\phi(t), \theta(t), \psi(t)$ as follows [12,13]:

$\hat{\phi}=\frac{1}{W} \int_{0}^{T} \phi(t) W(t) d t$

$\hat{\theta}=\frac{1}{W} \int_{0}^{T} \theta(t) W(t) d t$

$\hat{\psi}=\frac{1}{W} \int_{0}^{T} \psi(t) W(t) d t$ 
with $T$ = period of the loading cycle and $W(t)=$ weight function given by:

$W(t)=H\left[\sigma_{1}(t)-\sigma_{1, \max }\right]$

where $H[]$ is the Heaviside function $(H[x]=1$ for $x \geq 0, H[x]=0$ for $x<0)$, and $\sigma_{1, \max }$ is the maximum value (in the loading cycle) of the maximum principal stress $\sigma_{1}$. The proposed weight function is such that no averaging procedure is actually required (this makes the implementation of the criterion rather simple), since the averaged principal stress axes coincide with the instantaneous principal directions corresponding to the time instant at which the maximum principal stress $\sigma_{1}$ achieves its maximum value in the loading cycle.

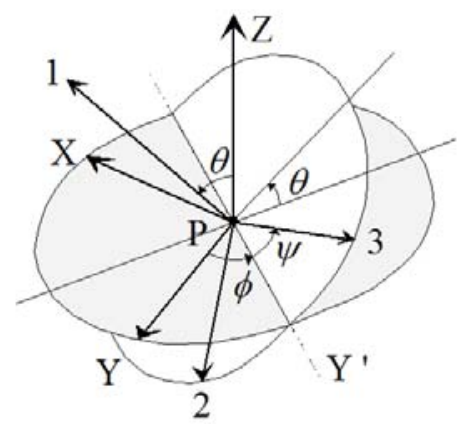

Figure 1: Principal stress directions 1,2,3 described through the Euler angles $\phi, \theta, \psi$.

\section{Critical plane and final fatigue fracture plane}

Fatigue crack propagation can be distinguished into two stages [22]: a first stage in which a crack nucleates along a shear slip plane (Stage 1, fatigue crack initiation plane or critical plane) and a second stage in which crack propagates in a plane normal to the direction of the maximum principal stress (Stage 2, final fatigue fracture plane).

According to the present criterion, the normal to the estimated final fatigue fracture plane (Stage 2), which is the one observed post mortem at the macro level, is assumed to be coincident with the averaged direction $\hat{1}$ of the maximum principal stress $\sigma_{1}$ [14]. On the other hand, the critical plane (Stage 1) is the verification material plane, where fatigue strength assessment is to be performed.

The orientation of the critical plane has been proposed to be correlated with the averaged directions of the principal stress axes [15] and the empirical expression of the off angle $\delta$ between the normal $\mathbf{w}$ to the critical plane (where $\mathbf{w}$ belongs to the averaged principal plane $\hat{1} \hat{3}$ ) and the averaged direction $\hat{1}$ of the maximum principal stress $\sigma_{1}$ is given by:

$\delta=\frac{3 \pi}{8}\left[1-\left(\frac{\tau_{a f,-1}}{\sigma_{a f,-1}}\right)^{2}\right]$

Equation (3) is valid for hard metals, which are characterised by values of the ratio $\tau_{a f,-1} / \sigma_{a f,-1}$ ranging from $1 / \sqrt{3}$ to 1 . The off angle $\delta$ is assumed to be equal to 0 for $\tau_{a f,-1} / \sigma_{a f,-1}>1$, whereas $\delta$ is taken to be equal to $\pi / 4$ for $\tau_{a f,-1} / \sigma_{a f,-1}<1 / \sqrt{3}$.

\section{Mean value and amplitude of normal stress and shear stress}

The critical plane $\Delta$ passing through a given point $\mathrm{P}$ in a solid and the attached orthogonal coordinate system Puvw are considered (Fig.2), where the u-axis belongs to the plane formed by the w-axis (normal to the critical plane) and the Z- 
axis. The direction cosines of $\mathrm{U}-, \mathrm{V}$ - and $\mathrm{W}$-axis can be computed with respect to the PXYZ frame, as a function of the two angles $\varphi$ and $\vartheta$.

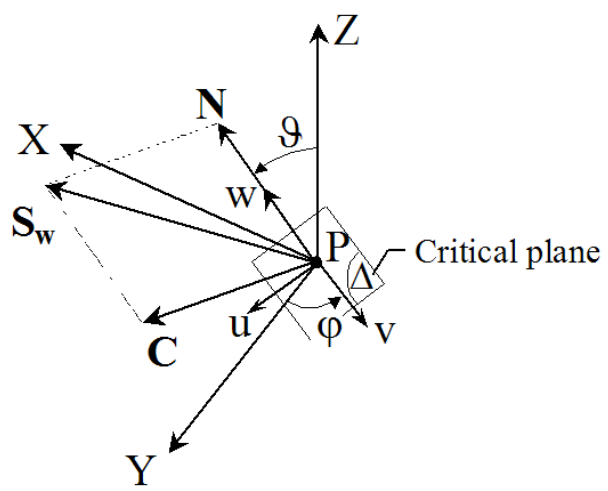

Figura 2: PXYZ and Puvw coordinate systems, with the $\mathrm{W}$-axis normal to the critical plane $\Delta$.

The stress vector $\mathbf{S}_{\mathbf{w}}$ acting at point $\mathbf{P}$, the normal stress vector $\mathbf{N}$ and the shear stress vector $\mathbf{C}$ acting on the critical plane are given by:

$$
\mathbf{S}_{\mathbf{w}}=\boldsymbol{\sigma} \cdot \mathbf{w} \quad \mathbf{N}=\left(\mathbf{w} \cdot \mathbf{S}_{\mathbf{w}}\right) \mathbf{w} \quad \mathbf{C}=\mathbf{S}_{\mathbf{w}}-\mathbf{N}
$$

For multiaxial constant amplitude cyclic loading, the direction of the normal stress vector $\mathbf{N}(\mathrm{t})$ is fixed with respect to time and consequently, the mean value $N_{m}$ and the amplitude $N_{a}$ of the vector modulus $N(t)$ can readily be calculated. On the other hand, the definitions of the mean value $C_{m}$ and amplitude $C_{a}$ are not unique owing to the generally timevarying direction of the shear stress vector $\mathbf{C}(t)$. The procedure proposed by Papadopoulos [23] to determine $C_{m}$ and $C_{a}$ is adopted [14].

\section{Fatigue strength estimation}

The multiaxial fatigue limit condition presented in Ref.[15] corresponds to a nonlinear combination of the maximum normal stress $\left(N_{\max }=N_{m}+N_{a}\right)$ and the shear stress amplitude $\left(C_{a}\right)$ acting on the critical plane:

$$
\left(\frac{N_{\max }}{\sigma_{a f,-1}}\right)^{2}+\left(\frac{C_{a}}{\tau_{a f,-1}}\right)^{2}=1
$$

As is well-known, the effect of a tensile mean normal stress superimposed upon an alternating normal stress strongly reduces the fatigue resistance of metals, while a mean shear stress superimposed upon an alternating shear stress does not affect the fatigue life [24]. Therefore, the following multiaxial fatigue limit condition is here adopted [18]:

$$
\left(\frac{N_{a, e q}}{\sigma_{a f,-1}}\right)^{2}+\left(\frac{C_{a}}{\tau_{a f,-1}}\right)^{2}=1
$$

where:

$$
N_{a, e q}=N_{a}+\sigma_{a f,-1}\left(\frac{N_{m}}{\sigma_{u}}\right)
$$


with $\sigma_{u}=$ ultimate tensile strength. Equation (7) is based on the well-known linear interaction between normal stress amplitude and normal stress mean value (diagram of Goodman).

In order to transform the actual periodic multiaxial stress state into an equivalent uniaxial normal stress state (with amplitude $\left.\sigma_{a, e q}\right)$, Equation (6) can be rewritten as follows:

$\sigma_{a, e q}=\sqrt{N_{a, e q}^{2}+\left(\frac{\sigma_{a f,-1}}{\tau_{a f,-1}}\right)^{2} C_{a}^{2}}=\sigma_{a f,-1}$

For fatigue strength assessment at finite life, the fatigue limits $\sigma_{a f,-1}$ and $\tau_{a f,-1}$ appearing in Eqs (6) and (8) should be replaced by the corresponding fatigue strengths. Hence, using a Basquin-like relationship for both fully reversed normal stress $\left(\sigma_{a f,-1}^{\prime}=\sigma_{a f,-1}\left(N_{f} / N_{0}\right)^{m}\right.$, with $\sigma_{a f,-1}^{\prime}=$ fatigue strength for fully reversed normal stress at finite life $N_{f}$, and $N_{0}=$ reference number of loading cycles, e.g. $\left.2 \cdot 10^{6}\right)$ and fully reversed shear stress $\left(\tau_{a f,-1}^{\prime}=\tau_{a f,-1}\left(N_{f} / N_{0}\right)^{m^{*}}\right.$, with $\tau_{a f,-1}^{\prime}=$ fatigue strength for fully reversed shear stress at finite life $N_{f}$ ), Equation (8) becomes:

$$
\sqrt{\left(N_{a, e q}^{\prime}\right)^{2}+\left(\frac{\sigma_{a f,-1}}{\tau_{a f,-1}}\right)^{2}\left(\frac{N_{f}}{N_{0}}\right)^{2 m}\left(\frac{N_{0}}{N_{f}}\right)^{2 m^{*}} C_{a}^{2}}=\sigma_{a f,-1}\left(\frac{N_{f}}{N_{0}}\right)^{m}
$$

where the equivalent normal stress amplitude, $N_{a, e q}^{\prime}$, at finite life $N_{f}$ is given by:

$$
N_{a, e q}^{\prime}=N_{a}+\sigma_{a f,-1}\left(\frac{N_{f}}{N_{0}}\right)^{m}\left(\frac{N_{m}}{\sigma_{u}}\right)
$$

Now substituting Eq.(10) into Eq.(9), the number $N_{f}$ of loading cycles to failure can be determined by solving the nonlinear equation obtained.

\section{EXPERIMENTAL APPLICATIONS AND DISCUSSION}

I $\mathrm{n}$ the present section, the above fatigue criterion is applied to some experimental results, obtained from finite-life fatigue tests, related to welded joints subjected to bending (or tension), torsion, in-phase or out-of-phase combined bending (or tension) and torsion [11,19-21]. Some mechanical characteristics of the materials examined are reported in Ref. [18].

The values of the following material parameters: $\sigma_{a f,-1}, \tau_{a f,-1}, m$ and $m^{*}$, required by the proposed criterion to evaluate fatigue life, are those determined in Ref.[25] by Susmel and Tovo, who analysed the experimental data reported in Refs [11, 19-21]. Note that such parameters have been deduced by Susmel and Tovo [25] analysing the above experimental data found in the literature, except for the data set reported in Ref.[19], since the S-N curve related to bending cannot be determined due to the limited number of experimental results. Therefore, the values given by Eurocode 3 [2] are herein adopted for the above parameters.

The geometries of the specimens examined are circular tube-to-plate joints, box beams with longitudinal attachments and square tube-to-plate joints.

The most critical point (point P) for fatigue crack initiation is assumed to be at the weld toe, since cracks in welded structural components often initiate along the weld toes, where high stress concentrations and local geometric irregularities exist. 
The C-S criterion is hereafter applied in terms of nominal stresses. The nominal loading paths analysed are reported in Fig.3, where normal stress $\sigma_{X}$ and shear stress $\tau_{X y}$ at point $\mathrm{P}$ are the stress perpendicular and that tangent to the weld bead, respectively.
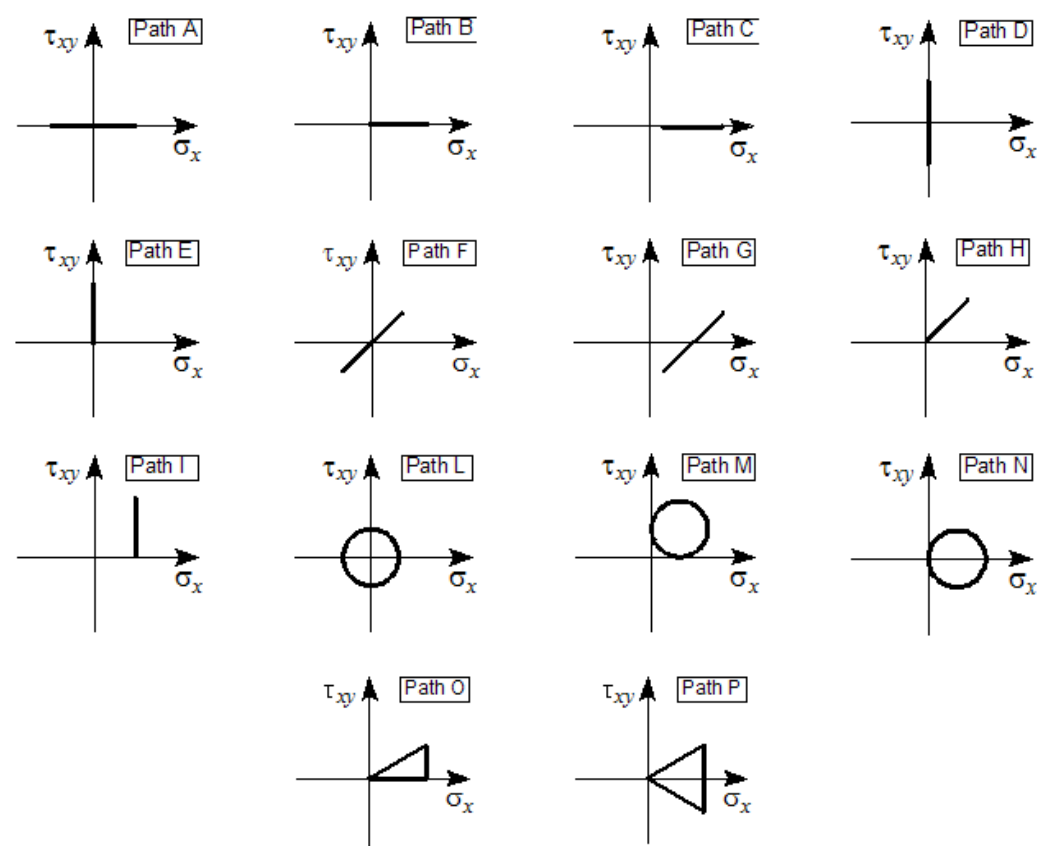

Figure 3: Summary of nominal loading paths.

In order to determine the mean directions of the principal stress axes at point $\mathrm{P}$, the instantaneous values of the principal Euler angles are averaged by employing the weight function $W(t)$ proposed in Eq.(2). Then, the angle $\delta$ between $\hat{1}$ and $\mathbf{w}$ is determined by using Eq.(3). As is mentioned above, such an equation was originally proposed in Ref.[15] for hard metals which are characterised by values of the ratio $\tau_{a f,-1} / \sigma_{a f,-1}$ ranging from $1 / \sqrt{3}$ to 1 . For data set reported in Ref.[21] the ratio $\tau_{a f,-1} / \sigma_{a f,-1}$ is greater than 1 . This is to be expected because the fatigue limits $\sigma_{a f,-1}$ and $\tau_{a f,-1}$ are derived by testing welded specimens [11, 19-21] and, therefore, the values of such parameters are influenced by the presence of fillet welds. As is stated in Section 2.2, the off angle $\delta$ is assumed to be equal to 0 when $\tau_{a f,-1} / \sigma_{a f,-1}>1$.

Fig. 4 shows a comparison between experimental fatigue life $\left(N_{\text {exp }}\right)$ and calculated fatigue life $\left(N_{\text {cal }}\right)$ for each experimental data set considered above, where the solid line indicates $N_{c a l}=N_{\text {exp }}$, the dashed lines correspond to $N_{\text {cal }} / N_{\text {exp }}$ equal to $1 / 2$ and 2 (scatter band with coefficient 2) and the dashed-dotted lines correspond to $N_{\text {cal }} / N_{\text {exp }}$ equal to $1 / 3$ and 3 (scatter band with coefficient 3). Note that the run-out tests are excluded from the present analysis. Tab. 1 reports the number of specimens tested and the percentage of the results of fatigue life estimation included into the scatter band with coefficient 2 and into the scatter band with coefficient 3 , for each data set analyzed.

The quality of the predictions made by applying the extended C-S criterion can be evaluated through an error index, $I(\%)$, defined as follows:

$I= \begin{cases}\frac{N_{\text {exp }}-N_{c a l}}{N_{\text {exp }}} \% & \text { for } N_{c a l} \leq N_{\text {exp }} \\ \frac{N_{\text {exp }}-N_{c a l}}{N_{c a l}} \% & \text { for } N_{c a l}>N_{\text {exp }}\end{cases}$ 
For each data set presented above, the relative frequency of the error index is shown in Fig.5. The values of $I$, ranging from $-100 \%$ to $+100 \%$, have been separated in 20 classes of $10 \%$ range. Such a relative frequency represents the number of experimental tests whose error index falls in the interval considered, normalised with respect to the total number of tests. Note that a positive value of $I$ represents a conservative prediction.
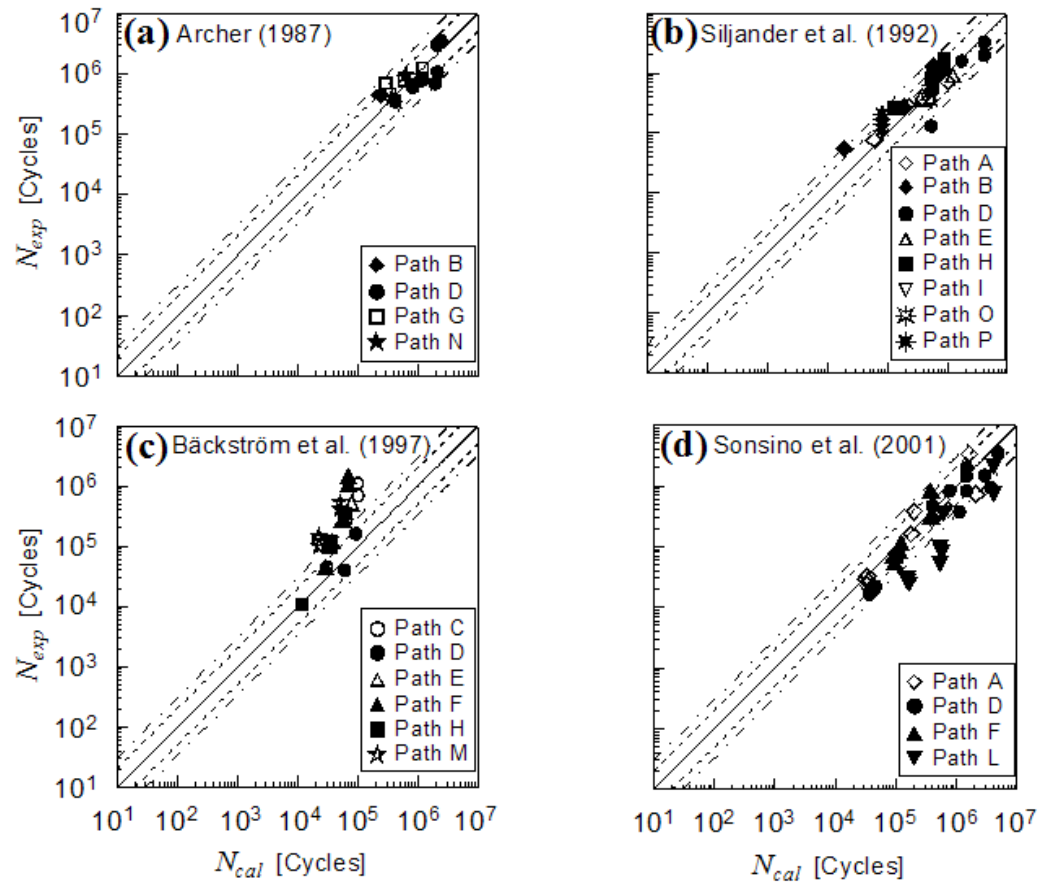

Figure 4: Experimental fatigue life $N_{\text {exp }}$ vs predicted fatigue life $N_{c a l}$ for each experimental data set analysed [11, 19-21].
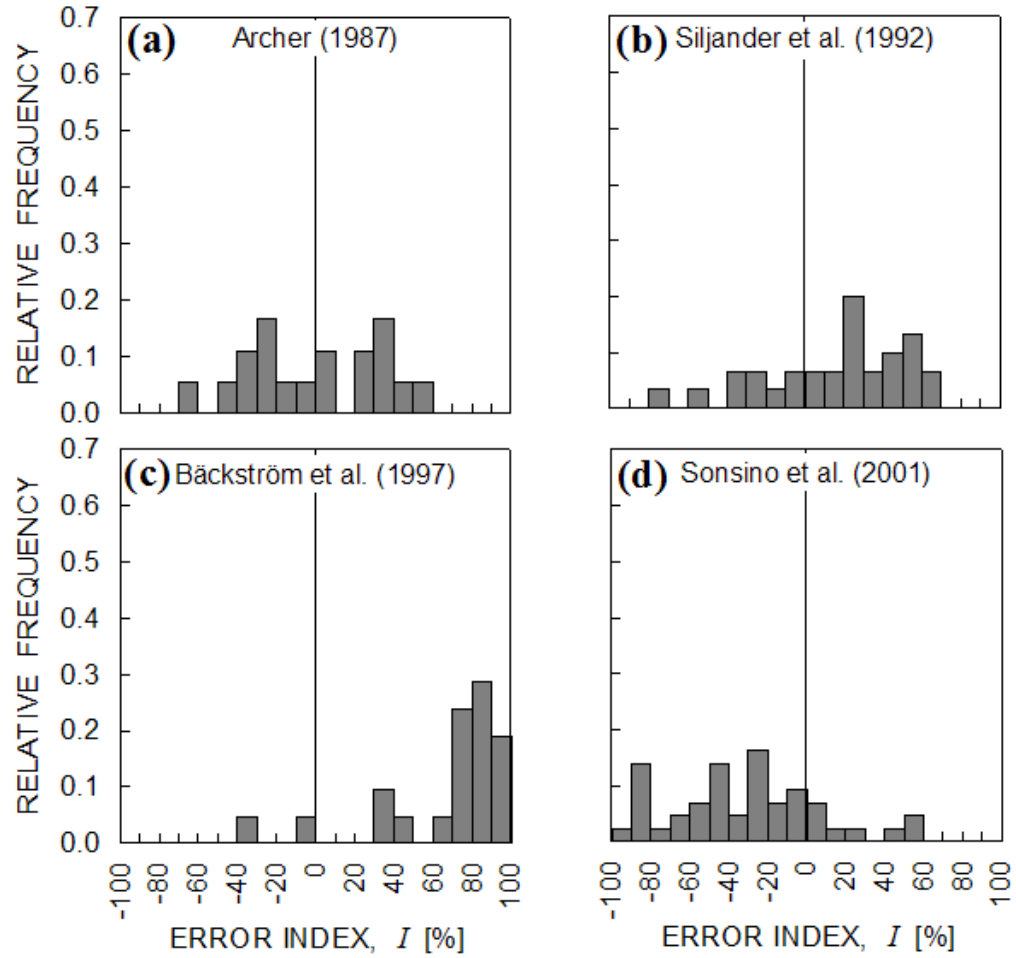

Figure 5: Error index distribution for each experimental data set analysed [11,19-21]. 


\begin{tabular}{lcccc}
\hline Reference & & $\begin{array}{c}\text { No. } \\
\text { specimens }\end{array}$ & $\begin{array}{c}\text { Scatter band 2 } \\
\%\end{array}$ & $\begin{array}{c}\text { Scatter band 3 } \\
\%\end{array}$ \\
Archer & {$[19]$} & 18 & 94 & 100 \\
Siljander et al. & {$[20]$} & 30 & 77 & 97 \\
Bäckström et al. & {$[21]$} & 21 & 24 & 29 \\
Sonsino et al. & {$[11]$} & 43 & 65 & 81 \\
\hline
\end{tabular}

Table 1: Percentage of the results included into the scatter bands with coefficients 2 and 3 , for each experimental data set analysed [11,19-21].

\section{CONCLUSIONS}

I $\mathrm{n}$ the present paper, the criterion proposed by Carpinteri and Spagnoli for both smooth and notched structural components is extended to the fatigue assessment of welded joints under in-phase or out-of-phase loadings. The averaged principal stress axes, determined through the weight function method, are used to predict the orientation of the critical plane where to perform the fatigue failure assessment. Then a fatigue failure criterion based on a nonlinear combination of an equivalent normal stress amplitude and the shear stress amplitude acting on the critical plane is employed to carry out such an assessment. The criterion proposed is applied to relevant experimental results, available in the literature, related to welded joints subjected to bending (or tension), torsion, in-phase or out-of-phase combined bending (or tension) and torsion. It can be remarked that, in most of the cases here examined, the fatigue life predictions of the present criterion fall within a scatter band of coefficient 3 .

\section{ACKNOWLEDGEMENTS}

he authors gratefully acknowledge the research support for this work provided by the Italian Ministry for University and Technological and Scientific Research (MIUR).

\section{REFERENCES}

[1] D. Radaj, (1990). Design and analysis of fatigue-resistant welded structures. Abington Publishing, Cambridge, UK.

[2] European Committee for Standardization. Eurocode 3. Design of steel structures. Part 1-1: General rules and rules for buildings. ENV 1993-1 (1992).

[3] E. Haibach, B. Atzori, Applied to Welded Joints in AlMg5. Society of Environmental Engineers Fatigue Group, Midyear Conference (1975).

[4] T.R. Gurney, Fatigue of Welded Structures. Cambridge University Press, Cambridge, UK (1979).

[5] P. Lazzarin, R. Tovo, Fatigue Fract. Engng. Mater. Struct., 21, (1998) 1089.

[6] P. Lazzarin, C.M.Sonsino, R.Zambardi, Fatigue Fract. Engng. Mater. Struct., 27 (2004) 127.

[7] D. Radaj, Z. Zheng, W. Möhrmann, Engng Fract. Mechs., 37 (1990) 933.

[8] D. Taylor, Engng Failure Analysis, 3 (1996) 129.

[9] C.M. Sonsino, D. Radaj, U. Brandt, H.P. Lehrke, Int. J. Fatigue, 21 (1999) 985.

[10] D. Taylor, N. Barrett, G. Lucano, Int. J. Fatigue, 24 (2002) 509.

[11] C.M. Sonsino, M. Kueppers, Fatigue Fract. Engng. Mater. Struct., 24 (2001) 309.

[12] A. Carpinteri, R. Brighenti, E. Macha, A. Spagnoli, Int. J. Fatigue, 21 (1999) 83.

[13] A. Carpinteri, R. Brighenti, E. Macha, A. Spagnoli, Int. J. Fatigue, 21 (1999)89.

[14] A. Carpinteri, R. Brighenti, A. Spagnoli, Fatigue Fract. Engng. Mater. Struct. 23 (2000) 355.

[15] A. Carpinteri, A. Spagnoli, Int. J. Fatigue, 23 (2001) 135.

[16] A. Carpinteri, A. Spagnoli, S. Vantadori, Fatigue Fract. Engng. Mater. Struct., 26 (2003) 515.

[17] A. Carpinteri, A. Spagnoli, S. Vantadori, D. Viappiani, Engng Fract. Mechs., 75 (2008) 1864.

[18] A.Carpinteri, A. Spagnoli, S. Vantadori, Int. J. Fatigue, 31 (2009) 188. 
[19] R. Archer, Proceedings of the Fatigue of Welded Constructions, Brighton, UK(1987) 63.

[20] A. Siljander, P. Kurath, F.V. Lawrence, in: Advances in Fatigue Lifetime Predictive Techniques, ASTM STP 1122, Philadelphia, PA. (1992) 319

[21] M. Bäckström, G. Marquis, Fatigue Fract. Engng. Mater. Struct. 24 (2001) 279.

[22] M.W. Brown, K.J. Miller, Fatigue Fract. Engng. Mater. Struct., 1 (1979) 231.

[23] I.V. Papadopoulos, Fatigue Fract. Engng. Mater. Struct., 21 (1998) 269.

[24] H.J. Gough, H.V. Pollard, W.J. Clenshaw, Aeronautical Res. Council Reports, R and M 2522, HMSO, London (1951)

[25] L. Susmel, R. Tovo, Fatigue Fract. Engng. Mater. Struct., 27 (2004) 1005. 